\title{
The nature of informational continuity of care in general practice
}

Gina Agarwal and Valorie A Crooks

\begin{abstract}
Background

The availability of patient information to practitioners forms the basis of informational continuity of care. Changes in family practice that now encourage multiphysician clinics have meant that informational continuity of care has become crucial because it is likely that a patient will not continuously see the same doctor. Therefore a review of the nature of informational continuity is useful.
\end{abstract}

Aim

To answer the question 'How is informational continuity developed in general practice?'.

Design of study

A rigorous systematic review of relevant electronic databases.

\section{Method}

Databases were searched for articles answering the research question. Articles focused on family medicine and informational continuity of care were included. Data from reviewed articles were independently extracted and reviewed by two researchers.

Conceptual and evidence-based articles were included.

\section{Results}

Initially, 193 articles were obtained from all five bibliographic databases; 57 were retained following title and abstract review. Of these, 34 articles were included in the final systematic review. Results show that informational continuity of care is developed using paper/electronic records and remembered information collectively, through a series of doctor-patient consultations over time. Obstacles to its development are practitioners not recording patient information and patients not disclosing important details.

Conclusion

These findings have implications for newer styles of primary care that may have a negative impact in the successful management of chronic illnesses in particular.

\section{Keywords}

continuity of care; information management; medical records; primary health care.

\section{INTRODUCTION}

Continuity of care is seen as an indicator of 'general practice quality' by the professional bodies of general practice in countries such as the UK, Canada, the US, and Australia. ${ }^{1-4}$ The term continuity of care covers many different aspects of continuity, specifically informational, longitudinal, and relational/interpersonal aspects. ${ }^{5,6}$ Informational continuity is understood to be the availability of patient information to providers throughout a healthcare system. ${ }^{7,8}$

With recent changes in family practice in some countries that now encourage large multiphysician group clinics and increased around-the-clock access to care, developing informational continuity of care has become crucial because in such care contexts it is likely that a patient will not continuously see the same doctor. Because of this, it is useful to review what we know about the nature of informational continuity of care within general practice, in order to inform decisions regarding service restructuring and the development of future primary care services. This paper reports the findings of a systematic review answering the question: 'How is informational continuity developed in family practice?'.

\section{METHOD}

The systematic review search strategy consisted of

G Agarwal, PhD Cand, MRCGP, CCFP, assistant professor, Department of Family Medicine, McMaster University, Hamilton, ON, Canada. VA Crooks, PhD, assistant professor, Department of Geography, Simon Fraser University, Burnaby, $B C$, Canada.

Address for correspondence

Gina Agarwal, Department of Family Medicine, McMaster University, 75 Frid Street, Hamilton, Ontario, L8P 4M3,

Canada. E-mail: gina.agarwal@gmail.com

Submitted: 7 February 2008; Editor's response: 4 April 2008; final acceptance: 21 July 2008.

(OBritish Journal of General Practice.

This is the full-length article of an abridged version published in print. Cite this article as: $B r J$ Gen Pract 2008; DOI: $10.3399 /$ bjgp08X342624. 
thoroughly searching the following electronic databases: MEDLINE (OVID) (1966 - week 1, May, 2006), CINAHL (OVID) (1982 - week 1, May, 2006), EMBASE (1980 - week 1, May, 2006) and PSYCHINFO (1806 - week 1, May, 2006), and Web of Science (1900 - week 1, May, 2006). Databases were searched using keywords that were agreed upon by the investigators after first being independently identified (Table 1). The databases selected for the search were also agreed upon by the investigators. Articles in English deemed relevant to the search were retrieved. Reference lists of reviewed articles were manually examined for further studies.

Titles obtained from the initial searches were independently reviewed by both investigators. Articles focusing on issues outside of general practice or other aspects of continuity of care were immediately excluded. After independently selecting titles for inclusion, the investigators met to determine which articles were to have abstract review. Following abstract review, a further meeting was held to determine inclusion for full article review. Articles selected for full review were read by both investigators and data extracted independently using the same extraction form.

Because of the nature of this review and the types of articles that were identified, the focus was on systematically reviewing the content of articles selected for full review rather than the study or protocol design. Numerous meetings were held during the full review stage to confirm both extracted information and also inclusion in or exclusion from the review. During this stage, the merits and qualities of articles over which there was disagreement were

\section{How this fits in}

Informational continuity of care is developed using paper/electronic records and remembered information collectively, through a series of doctor-patient consultations over time. Obstacles to its development are practitioners not recording patient information and patients not disclosing important details. These findings have implications for newer styles of primary care which may negatively impact the successful management of chronic illnesses in particular.

discussed until both reviewers were in agreement. Following this, all extracted information recorded on the data-extraction forms were recorded on an electronic spreadsheet.

\section{RESULTS}

Initially, 193 articles were obtained from all five bibliographic databases; 57 were retained following title and abstract review (Box 1). Of these, 34 articles were included in the final systematic review. Twenty articles read in full were excluded because they did not contain the elements required for inclusion once the full paper was examined, and three articles were unobtainable. The $\kappa$ score for agreement by reviewers at the title/abstract stage was 0.673 (standard error [SE] 0.17, $P=0.004$ ).

Of the 34 included articles, three reported on mixed-method studies, ${ }^{9-11}$ eight on qualitative studies, ${ }^{12-19} 10$ on quantitative studies, ${ }^{20-29}$ and the remaining 13 were commentary or review articles. ${ }^{30-42}$ Since there was little published literature on informational continuity of care, the researchers were compelled to include conceptual pieces (for

\section{Table 1. Search strategy employed.}

\begin{tabular}{|c|c|}
\hline Subject terms & MeSH terms \\
\hline Family practice & $\begin{array}{l}\text { Family Practice/ or family medicine.mp. or general practice.mp. or primary care.mp. or Primary Health Care/ } \\
\text { or general practitioner.mp. or Physicians, Family/ or Primary Health Care/ or Family Practice/or family } \\
\text { practitioner.mp. or primary care physician.mp. or family physician.mp. or family doctor.mp. or Primary Health } \\
\text { Care/ or primary care clinician.mp. or Community Health Centers/ or health care clinic.mp. or primary health } \\
\text { care clinic.mp. or primary health care } \$ \mathrm{mp} \text {. or family clinic.mp }\end{array}$ \\
\hline Informational continuity of care & $\begin{array}{l}\text { Continuity of Patient Care/ or informational continuity of care.mp. or Physician-Patient Relations/or medical } \\
\text { records.mp. or Medical Records/ or Medical Records Systems, Computerized/ or written medical } \\
\text { records.mp. or electronic medical records.mp. or Mental Recall/ or Memory/ or remembered information.mp. } \\
\text { or knowledge.mp. or Knowledge/ or Knowledge Bases/ or notes.mp. or casenotes.mp. or Medical History } \\
\text { Taking/ or medical history.mp. or patient history.mp. or past medical history.mp. or Physician-Patient } \\
\text { Relations/ or Communication/ or communication of information.mp. or patient charts.mp. or Medical } \\
\text { Records Systems, Computerized/ or patient records.mp. or patient medical history.mp. or doctor-patient } \\
\text { communication.mp. or doctor-patient interaction.mp. or professional knowledge.mp. or physician- patient } \\
\text { relations.mp. or Physician-Patient Relations/ or Health Knowledge, Attitudes, Practice/ or lay knowledge.mp. }\end{array}$ \\
\hline Establishment and maintenance & $\begin{array}{l}\text { Establish\$ } \\
\text { Maint\$ } \\
\text { Develop\$ }\end{array}$ \\
\hline Dimensions & $\begin{array}{l}\text { Dimension\$ } \\
\text { Aspect\$ } \\
\text { Level\$ }\end{array}$ \\
\hline
\end{tabular}




\section{Box 1. Results of search strategy. \\ IDENTIFICATION \\ 193 articles sourced from 5 databases<smiles>[AlH]</smiles> \\ TITLE and ABSTRACT REVIEW \\ 57 selected for full review \\ 136 excluded<smiles>[AlH][AlH]</smiles> \\ ARTICLE REVIEW \\ 34 included \\ 23 excluded ( 20 did not contain needed elements, 3 unobtainable)

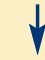 \\ OUTCOME \\ 34 articles accepted for review}

example, commentaries and review articles) in this review. These pieces were often written by leaders in the field of continuity; the researchers therefore felt justified in including information extracted from these articles in the review. The work for 15 articles was undertaken in the UK, 12 in the US, three in Canada, and one each in Malaysia, Australia, Norway, and the Netherlands. The reviewed articles are summarised in Table 2.

The systematic review revealed important but scattered details about the development and use of informational continuity of care within family practice. These are presented next under the themes that arose from the article review.

\section{Nature of the continuous record}

In primary care, the medical record forms the basis upon which informational continuity of care is built. This record is constructed using 'mature information' (that is historical medical information as opposed to current information only), ${ }^{41}$ and established throughout multiple consultations over time with the patient and his or her family. ${ }^{28,30,41}$ Information can be stored in paper records, electronically, or in practitioners' memories. Computerised (for example, electronic medical records [EMRs]) and paper records store different types of information..$^{20}$ Informational continuity may be better when doctors have to 'hand over' records to other care providers, otherwise they may rely on memory alone. ${ }^{41}$ While GPs are traditionally medical information coordinators, nurses or receptionists are also involved in developing informational continuity of care because of their roles in record keeping. ${ }^{16}$

\section{Importance of the doctor's memory}

Although GPs frequently use recorded information,

they also use remembered information to produce better health outcomes for the patient, ${ }^{25}$ and enhance the effectiveness of their care. ${ }^{29,31}$ They draw specifically on their own stored knowledge of patients' medical histories and social/lifestyle circumstances ${ }^{30}$ Importantly, the duration and depth of the doctor-patient relationship shapes information transfer and record keeping, taking at least a few years to establish a good knowledge base. ${ }^{14}$ Such a knowledge base, and the use of remembered information, is particularly important at extremes of life, including in the palliative care context. ${ }^{32}$ Having informational continuity of care is also useful when treating patients experiencing mental illness, ${ }^{31}$ and psychological disorders. ${ }^{21}$ Here, lack of specific knowledge has been regarded as a hindrance to patient management. ${ }^{21}$ Another general hindrance is that doctors typically ask long-term patients for details of their medical histories and social/lifestyle circumstances only on rare occasions, ${ }^{9}$ which leaves them without such details to store as remembered information.

\section{Patient input into recorded information}

The duration and depth of the doctor-patient relationship shapes information transfer and record keeping, taking at least a few years to establish a good knowledge base. ${ }^{14}$ Patient input into record keeping is normal. Actually, $30 \%$ of patients enjoy discussing what is to be entered into their records. ${ }^{17}$ Such input may also be given in written form. New patients, for example, may complete their own medical history form for inclusion in their record. ${ }^{9}$ During periods when the formal record cannot be accessed (for example, during file transfer between clinics), a patient's own notes may be particularly welcomed. ${ }^{42}$ However, patients often select information about what they believe is important to be recorded, typically prioritising biomedical factors over socio-contextual or personal ones. ${ }^{18,34}$ It is not clear, in general, how well a patient's own augmentative notes will be received by his/her doctor. ${ }^{16,30,32}$

\section{DISCUSSION}

This systematic review reveals that informational continuity of care can be best developed using paper and electronic records and remembered information Although GPs have input, patients and practice staff also contribute to its development. Patients may want to have more of a say in what information gets recorded, but there is little opportunity for this unless asked for specifically by a practitioner - something that may jeopardise developing informational continuity of care. Other obstacles to developing continuity of care identified by the review include: 
Table 2. Reviewed articles (opinion-based conceptual articles (for example, essays, commentaries, reviews, editorials) are indicated by italics.

\begin{tabular}{|c|c|c|}
\hline Author(s), year published & Study design & Main points for informational continuity \\
\hline $\begin{array}{l}\text { Aaronson et al, } \\
2001^{12}\end{array}$ & $\begin{array}{l}\text { Qualitative survey of } 219 \text { family } \\
\text { medicine residency directors }\end{array}$ & $\begin{array}{l}41 \% \text { of respondents said EMRs negatively affected interactions with } \\
\text { patients. Historical patient information is used for health maintenance/ } \\
\text { laboratory flags/problem medication/patient lists. }\end{array}$ \\
\hline $\begin{array}{l}\text { Bertakis and Callahan, } \\
1992^{9}\end{array}$ & $\begin{array}{l}\text { Cross-sectional observations of doctor- } \\
\text { patient interactions in a university family practice; } \\
47 \text { interactions with established patients, } \\
36 \text { with new patients; interactions analysed }\end{array}$ & $\begin{array}{l}\text { Doctors typically ask information of established patients using valiated } \\
\text { Davis Observation Code only when it is relevant to a new medical } \\
\text { problem. There is less discussion of patients' family information in } \\
\text { established patient visits. }\end{array}$ \\
\hline $\begin{array}{l}\text { Burt et al, } \\
2004^{13}\end{array}$ & $\begin{array}{l}\text { Qualitative retrospective audit of GP } \\
\text { communications from } 13460 \text { patient } \\
\text { consultations in palliative care situations }\end{array}$ & $\begin{array}{l}\text { Updating patient information is central to the doctor's role. A lack of } \\
\text { informational continuity negatively impacts on palliative care specifically. }\end{array}$ \\
\hline $\begin{array}{l}\text { Desguin et al, } \\
1994^{30}\end{array}$ & Conceptual & $\begin{array}{l}\text { Families should keep information on prescriptions and health conditions. } \\
\text { Nurses can assist with updating medical records. } \\
\text { Medical records are important to illness management. } \\
\text { Recording social/familial information in EMRs is important. }\end{array}$ \\
\hline $\begin{array}{l}\text { Freeman, } \\
1984^{32}\end{array}$ & Conceptual & $\begin{array}{l}\text { Informational continuity is better when doctors 'hand over' records. } \\
\text { Relying on memory alone for patient information may not be a good } \\
\text { strategy. Rather, memory is an aid for consistency along with medical } \\
\text { record. There is no consistency in how much information recorded in a } \\
\text { patient's record. }\end{array}$ \\
\hline $\begin{array}{l}\text { Freeman et al, } \\
2003^{33}\end{array}$ & Conceptual & $\begin{array}{l}\text { Having informational continuity can overcome the negative outcomes of } \\
\text { lacking interpersonal continuity of care. Sometimes doctor and patient } \\
\text { want a fresh start with regard to informational continuity (that is, a new } \\
\text { record). Some GPs may deliberately not record contextual information so } \\
\text { that s/he becomes the sole keeper of this information. } \\
\text { Continuity is still maintained, with that practitioner only. }\end{array}$ \\
\hline $\begin{array}{l}\text { Freer, } \\
1980^{34}\end{array}$ & Conceptual & $\begin{array}{l}\text { Patient health diaries used in research have been found to be more } \\
\text { efficient than retrospective health interviews. It may be possible to use } \\
\text { health diaries clinically, but the methods for doing this remain unclear. }\end{array}$ \\
\hline $\begin{array}{l}\text { Guthrie and Wyke, } \\
2000^{35}\end{array}$ & Conceptual & $\begin{array}{l}\text { Continuity is enhanced by the use of EMRs. Chronically ill patients } \\
\text { typically spend ten minutes explaining their health history to new GPs. } \\
\text { Personal continuity is defined as the ongoing doctor-patient relationship } \\
\text { and it ensures care takes account of a patient's personal/social context. }\end{array}$ \\
\hline $\begin{array}{l}\text { Hamilton et al, } \\
2003^{20}\end{array}$ & $\begin{array}{l}\text { Cross-sectional retrospective } \\
\text { case-control with cancer patients } \\
\text { from } 21 \text { general practices }\end{array}$ & $\begin{array}{l}\text { Computerised and paper records record different types of patient } \\
\text { information. For example, some computer systems have little } \\
\text { 'free space' for contextual material. Accurate records are especially } \\
\text { needed in case of patient complaints or legal action. Information and } \\
\text { patient follow-ups can be lost if there is no personal continuity. } \\
\text { A hybrid system of paper records and computer records is more } \\
\text { comprehensive (computer records have more telephone conversations } \\
\text { recorded, paper charts have more home visits and symptoms recorded). }\end{array}$ \\
\hline $\begin{array}{l}\text { Hegan, } \\
2003^{36}\end{array}$ & Conceptual & $\begin{array}{l}\text { Medical records are important as they ensure past consultations } \\
\text { can be communicated. They should allow the person reading to } \\
\text { re-construct the event. Effective communication with colleagues is } \\
\text { needed for continuity of care between practitioners. }\end{array}$ \\
\hline $\begin{array}{l}\text { Hennen, } \\
1975^{37}\end{array}$ & Conceptual & $\begin{array}{l}\text { Continuity of information is vital in cementing the } \\
\text { interprofessional relationships in the office (as different } \\
\text { professionals see patients). The medical record is the key to this. }\end{array}$ \\
\hline $\begin{array}{l}\text { Hjortdahl et al, } \\
1992^{14}\end{array}$ & Qualitative survey of $133 \mathrm{GPs}$ & $\begin{array}{l}\text { Prior knowledge of a patient (for example, about medical history, } \\
\text { personality, social network) affects decision making. } \\
\text { GPs are information coordinators. The duration and depth of } \\
\text { doctor-patient relationship shapes accumulated knowledge; it takes at } \\
\text { least a few years (1-5 years) to establish a good knowledge base. }\end{array}$ \\
\hline
\end{tabular}




\section{Table 2 continued. Reviewed articles (opinion-based conceptual articles (for example, essays, commentaries, reviews, editorials) are indicated by italics.}

\author{
Hjortdahl, \\ $1992^{21}$ \\ Survey of 133 GPs after \\ doctor-patient interaction
}

A doctor's prior knowledge of patient assists with decision making. For example, prior knowledge is 'helpful' in $44 \%$ of cases, 'useful' in $66 \%$ of cases, and a 'great help' in $30 \%$. In $8 \%$ of cases a lack of knowledge was deemed a 'hindrance'.

Hjortdahl, Conceptual

$2001^{38}$

Continuity builds relationships between doctor and patient.

The patient needs to trust the doctor in order to establish continuity. Continuity may be used to develop a doctor's clinical knowledge/skills. Informational continuity is unlikely to replace interpersonal continuity of care. Doctors possess integrated knowledge gathered over time.

\begin{tabular}{ll}
$\begin{array}{l}\text { Kearley et al, } \\
2001^{22}\end{array}$ & $\begin{array}{l}\text { Qualitative interviews and cross-sectional survey } \\
\text { of } 996 \text { patients and } 284 \text { doctors in } 18 \text { practices }\end{array}$ \\
\hline $\begin{array}{l}\text { Kibbe et al, } \\
2004^{39}\end{array}$ & Conceptual
\end{tabular}

Informational continuity cannot replace interpersonal continuity in the delivery of quality of care.

A patient's memory is sometimes needed when reassembling information missing from the recorded record. Patients can relay EMRs between physicians. Continuous connectivity between patients, families, and doctors is an element of continuity. A portable, patient-held record (on smart-card or USB) can be a source of empowerment.

Kravitz et al, Cross-sectional survey

$1993^{23} \quad$ (database data) of 1751 patients

Patients may not remember accurately what they have been told by doctors. For example, $>90 \%$ of respondents remembered to take medications. Fewer remembered being told about diet and lifestyle advice. Therefore, patients' memories may be selective.

\begin{tabular}{ll}
\hline Lester et al, & Cluster randomised \\
$2003^{24}$ & controlled trial of 201 patients
\end{tabular}

\begin{tabular}{ll}
\hline Liaw et al, & Two focus groups held with \\
$1992^{15}$ & 21 randomly selected patients from \\
& family practice and walk-in clinics
\end{tabular}

\begin{tabular}{ll}
\hline Litaker et al, & $\begin{array}{l}\text { Survey of retrospective cohort } \\
\text { of a specific patient group of } 3718 \text { patients }\end{array}$
\end{tabular}

\begin{tabular}{ll}
\hline $\begin{array}{l}\text { Mandl et al, } \\
2001^{40}\end{array}$ & Conceptual \\
\hline $\begin{array}{l}\text { Moore and Busing, } \\
1993^{6}\end{array}$ & $\begin{array}{l}\text { Qualitative survey of } 13 \text { family } \\
\text { medicine residency programme directors }\end{array}$
\end{tabular}

Parchman et al, Time series (cross-sectional $2002^{26} \quad$ prospective cohort) of 256 patients

\begin{tabular}{|c|c|c|}
\hline $\begin{array}{l}\text { Risdale and Hudd, } \\
1994^{17}\end{array}$ & Qualitative interviews with 39 patients & $\begin{array}{l}\text { Computers are an efficient tool for quickly accessing information and for } \\
\text { cross-referencing. Information is accessed in computerised records } \\
\text { faster than in hand-held ones. }\end{array}$ \\
\hline $\begin{array}{l}\text { Risdale and Hudd, } \\
1997^{18}\end{array}$ & $\begin{array}{l}\text { Qualitative interviews with } \\
30 \text { patients from a specific clinic }\end{array}$ & $\begin{array}{l}\text { Patients have views about what information they see as needed for } \\
\text { the EMRs. Lifestyle information and biological risk factors are } \\
\text { appropriate. Personal comments and serious illness are not, unless } \\
\text { discussed in advance (mental illness is also a concern). Doctors need to } \\
\text { develop ways patients can evaluate and access their information. }\end{array}$ \\
\hline $\begin{array}{l}\text { Rogers and Curtis, } \\
1980^{41}\end{array}$ & Conceptual & $\begin{array}{l}\text { Mature knowledge pertains to information built up about the patient and } \\
\text { his/her family. Telecommunications should be recorded on a patient's } \\
\text { record. The patient is more likely to disclose personal information when } \\
\text { s/he has an established record with the doctor. The patient's willingness } \\
\text { to provide important contextual and health information is implicit with the } \\
\text { goal of creating continuity of care. }\end{array}$ \\
\hline
\end{tabular}

The patient-held record is valued as a communication tool, particularly by patients with chronic stable schizophrenia. Patient-held records did not improve outcomes for patients with schizophrenia, although caseworkers/GPs found them useful.

Sharing information assists in establishing interpersonal continuity. Though personal qualities and competence of a doctor are important, patients felt it did not matter who the doctor was as long as medical records were available to ensure consistency. Ten patients wanted to see a regular GP who knows their personal/medical histories.

Informational continuity provides a knowledge base accessible to all clinicians, ideally through a single electronic record accessible to all healthcare providers.

Feelings of privacy and control will enhance a patient's sharing of information during an appointment.

A nurse/receptionist who coordinates information/appointments is to be the most important person in establishing continuity from the patient's view. Computer records summarise patient history/ previous care.

With increasing continuity, trust in doctors increases and patients are more likely to divulge information regarding the social context relevant to health. Patient recall varies according to the outcomes of the previous consultation. For example, certain recommendations made by the doctor are more or less likely to be remembered. This could influence whether or not patients give correct information to their doctors. faster than in hand-held ones. discussed in advance (mental illness is also a concern). Doctors need to

Mature knowledge pertains to information built up about the patient and his/her family. Telecommunications should be recorded on a patient's s/he has an established record with the doctor. The patient's willingness goal of creating continuity of care. 


\section{Table 2 continued. Reviewed articles (opinion-based conceptual articles (for example, essays, commentaries, reviews, editorials) are indicated by italics.}

\author{
Rowan et al, \\ $2002^{27}$ \\ Cross-sectional survey of 134 \\ family medicine preceptors
}

Coordinated medical records are important and enhance physicians' abilities to recognise information about patients' problems/therapies; problem lists, medical lists and computers help this. Looking at the correlation with longitudinality of relationships, coordinated medical records overall scored R2 0.0639 , compared with, R2 0.1168 (regular medical records). GPs may need computer training to enhance informational continuity of care.

Schers et al, $\quad$ Cross-sectional postal survey of 873

$2003^{28} \quad$ family practice patients

Use of the computer as an information storage system may lead to more people having access to the information than the patient wants. Because of this, patients may withhold information or not disclose as much. Patients agreed that most aspects of their health histories were important for their personal GP to know, and should be accessible to the on-call GP. Older patients were more comfortable with multiple points of access to medical records. Doubts about the confidentiality of the practice may lead the patient to confide in their GP less. Access to private information should be given by patients to certain staff members. The doctor is not the only person seeing records; because of this, there may be no control over confidentiality in larger practices.

\begin{tabular}{|c|c|c|}
\hline $\begin{array}{l}\text { Starfield et al, } \\
1976^{29}\end{array}$ & Random chart pulls of 200 patients & $\begin{array}{l}\text { Recording certain types of information enhances the effectiveness of } \\
\text { care. Medical records are superior to doctors' recollections. }\end{array}$ \\
\hline $\begin{array}{l}\text { Starfield et al, } \\
1979^{10}\end{array}$ & $\begin{array}{l}\text { Observations of doctor-patient } \\
\text { interactions and chart pulls of } 104 \\
\text { patients with return visits scheduled }\end{array}$ & $\begin{array}{l}\text { Physicians routinely do not record certain types of information. } \\
\text { Quality of the medical record is linked to the quality of care. Doctors } \\
\text { are likely to recall important issues recorded on the health record. }\end{array}$ \\
\hline $\begin{array}{l}\text { The Bolton Research } \\
\text { Group, } 2000^{19}\end{array}$ & $\begin{array}{l}\text { Qualitative survey of } 756 \\
\text { patients in } 10 \text { group practice clinics }\end{array}$ & $\begin{array}{l}\text { Confidentiality allows patients to share information with doctors. Patients } \\
\text { believed that GPs should act as gatekeepers of the medical record. }\end{array}$ \\
\hline Thompson, $1989^{42}$ & Conceptual & $\begin{array}{l}\text { Patients should have their own summary of their chart to use when } \\
\text { travelling, when switching doctors, and when seeking acute care. The } \\
\text { doctor should establish a patient-based record, so that when admission/ } \\
\text { intervention is needed, all the information will be there. Sometimes } \\
6 \text { months can elapse between the new GP getting records in a } \\
\text { transfer situation. }\end{array}$ \\
\hline Toms, $1977^{11}$ & $\begin{array}{l}\text { Multi-qualitative method and } \\
\text { cross-sectional case study of } 30 \\
\text { families who had lost their family doctors }\end{array}$ & $\begin{array}{l}\text { It may fall to the patient to ensure getting records } \\
\text { transferred and thus ultimately getting continuity. } \\
\text { There is no 'usual practice' of transferral of practice - } \\
\text { each doctor is left to decide how this should be done. }\end{array}$ \\
\hline
\end{tabular}

practitioners not recording information shared by patients in the form of notes or information transmitted verbally; patients not disclosing important details, due to lack of knowledge about what practitioners perceive as important; and practitioners not asking about patients' lifestyles often enough. There may be reasons as to why these events are not occurring as frequently as they should, such as time pressures encountered by practitioners, the complexity of cases, and clinic procedure issues.

Patients' lifestyle and psychosocial information, though important for many reasons, is difficult to systematically store in the permanent record and may be more easily held as remembered information. If this is the case, then more suitable venues for storing this information should be developed that are easy to access and update. Education could assist patients with determining what lifestyle and psychosocial information to share with practitioners, including that which is specific to particular health conditions. Practitioners having greater ease of access to this information, including by request and also that which is offered up-front by patients, could assist in the improvement of informational continuity of care.

Despite the increasing desire to shift to computerised medical information storage via the EMR in many health systems, the impact of this on informational continuity of care has yet to be fully explored. Although computerised records are clearly helpful in situations where there are many care providers, as has been pointed out above, such records may not be able to capture all the nuances of hand-held and remembered information in an easily retrievable way. Furthermore, the authors' own research with chronically ill patients and their caregivers has revealed that the use of computers during consultations for purposes such as accessing EMRs could negatively affect both the conversational 
flow and, ultimately, information sharing. ${ }^{43}$ Specifically, recording information on computers during consultations was thought to lead to moreimpersonal interactions. This clearly has negative implications for the development of informational continuity of care. Given the lack of consideration paid to this issue in the reviewed articles, this is an important area for further exploration.

Given that the population of the Western world is aging, ${ }^{44}$ that we are burdened by more chronic and psychosocial disease, ${ }^{44,45}$ and the knowledge that informational continuity of care is particularly important in psychosocial, complex, and palliative care situations, newer clinic arrangements not attentive to the development of such continuity could be problematic. In clinics where patients are seen by different practitioners who do not have access to long-term remembered information, the provision of quality care to these populations, and others, may be challenged. Although attempts are being made to improve access to primary care, ${ }^{46}$ mandating that patients see multiple providers may be hindering the delivery of quality care. However, this has not been extensively researched. Future research should therefore look at the quality of informational continuity in various care settings from both providers' and patients' perspectives, in different models of healthcare delivery.

Ultimately, the doctor-patient relationship still remains the main vehicle that facilitates information transfer and the development of informational continuity of care in general practice. New models of care that facilitate and not hinder its development within general practice must be encouraged and developed.

\section{Funding body}

A Canadian Institutes of Health Research (CIHR) Interdisciplinary Capacity Enhancement (ICE) subgrant (through the Health Care, Technology \& Place [HCTP] CIHR Strategic Training Institute) provided research funding. Valorie Crooks received stipendiary funding through a CIHR Strategic Training Postdoctoral Fellowship in HCTP and a Canadian Health Services Research Foundation/CIHR Postdoctoral Fellowship in Health Services Research during the study period. Gina Agarwal was funded by a postdoctoral fellowship award from the Canadian Diabetes Association and also received stipendiary funding through a CIHR Strategic Training Postdoctoral Fellowship in HCTP during the study period

Ethical approval

McMaster University Health Sciences Research Ethics Board Approval (06-173)

\section{Competing interests}

The authors have stated that there are none.

Discuss this article

Contribute and read comments about this article on the Discussion Forum: http://www.rcgp.org.uk/bjgp-discuss

\section{REFERENCES}

1. Royal College of General Practitioners. Curriculum statement 1 Being a general practitioner (Report). London: Royal College of General Practitioners, 2005.
2. College of Family Physicians of Canada. Four principles of family medicine. http://www.cfpc.ca/English/cfpc/about\%20us/principles/ default.asp?s=1 (accessed 24 Sep 2008).

3. Green L, Graham R, Bagley B, et al. Task Force 1. Report of the task force on patient expectations, core values, reintegration, and the new model of family medicine. Ann Fam Med 2004; 2 : S33-S50.

http://www.annfammed.org/cgi/content/full/2/suppl_1/s33 (accessed 17 Sep 2008).

4. Royal Australian College of Family Physicians. RACGP Standards for general practices. Standard 1.5 Continuity of care - evidence base. Victoria, Australia: RACGP, 2005.

http://www.racgp.org.au/standards/15/evidencebase (accessed 17 Sep 2008).

5. Saultz JW, Albedaiwi W. Interpersonal continuity of care and patient satisfaction: a critical review. Ann Fam Med 2004; 2(5): $445-451$.

6. Haggerty JL, Reid RJ, Freeman GK, et al. Continuity of care: a multidisciplinary review. BMJ 2003; 327(7425): 1219-1221.

7. Wall EM. Continuity of care and family medicine. J Fam Pract 1981; 13(5): 655-664

8. Hansen MF. Continuity of care in family practice. J Fam Pract 1975; 2(6): 439-444.

9. Bertakis KD, Callahan EJ. A Comparison of initial and established patient encounters using the Davis Observation Code. Fam Med 1992; 24(4): 307-311.

10. Starfield B, Steinwachs D, Morris I, et al. Concordance between medical records and observations regarding information on coordination of care. Med Care 1979; 17(7): 758-766.

11. Toms WB. An analysis of the impact of the loss of a primary care physician on a patient population. J Fam Pract 1977; 4(1): 115-120.

12. Aaronson JW, Murphy-Cullen CL, Chop WM, Frey RD. Electronic medical records: the family practice resident perspective. Fam Med 2001; 33(2): 128-132.

13. Burt J, Barclay S, Marshall N, et al. Continuity within primary palliative care: an audit of general practice out-of-hours cooperatives. J Public Health 2004; 26(3): 275-276.

14. Hjortdahl P, Laerum E. Continuity of care in general practice: effect on patient satisfaction. BMJ 1992; 304(6837): 1287-1290.

15. Liaw ST, Litt J, Radford A. Patient Perceptions of Continuity of Care: Is There a Socioeconomic Factor? Fam Pract 1992; 9(1): 9-14

16. Moore L, Busing N. Continuity of care in the family medicine residency. Can Fam Physician 1993; 93: 531-534.

17. Ridsdale L, Hudd S. Computers in the consultation: the patient's view. Br J Gen Pract 1994; 44(385): 367-369.

18. Risdale L, Hudd S. What do patients want and not want to see about themselves on the computer screen: a qualitative study. Scand J Prim Health Care 1997; 15(4): 180-183.

19. The Bolton Research Group. Patients' knowledge and expectations of confidentiality in primary health care: a quantitative study. $\mathrm{Br} J$ Gen Pract 2000; 50(460): 901-902.

20. Hamilton WT, Round AP, Sharp D, Peters TJ. The quality of record keeping in primary care: a comparison of computerised, paper and hybrid systems. Br J Gen Pract 2003; 53(497): 929-33.

21. Hjortdahl P. The influence of general practitioners' knowledge about their patients on the clinical decision-making process. Scand J Prim Health Care 1992; 10(4): 290-294.

22. Kearley KE, Freeman GK, Heath A. An exploration of the value of the personal doctor-patient relationship in general practice. $\mathrm{Br} J$ Gen Pract 2001; 51(470): 712-718.

23. Kravitz RL, Hays RD, Sherbourne CD, et al. Recall of recommendations and adherence to advice among patients with chronic medical conditions. Arch Intern Med 1993; 153(16): 1869-1878.

24. Lester H, Allan T, Wilson S, et al. A cluster randomised controlled trial of patient-held medical records for people with schizophrenia receiving shared care. Br J Gen Pract 2003; 53(3): 197-203

25. Litaker D, Ritter C, Ober S, Aron D. Continuity of care and cardiovascular risk factor management: does care by a single clinician add to informational continuity provided by electronic medical records. Am J Manag Care 2005; 11(11): 689-696.

26. Parchman ML, Pugh JA, Noel PH, Larme AC. Continuity of care, self-management behaviours, and glucose control in patients with 
type 2 diabetes. Med Care 2002; 40(2): 137-144.

27. Rowan MS, Lawson B, MacLean C, Burge F. Upholding the principles of primary care in preceptors' practices. Fam Med 2002; 34(10): 744-749.

28. Schers K, van den Hoogen H, Grol R, van den Bosch W. Continuity of information in general practice - patient views on confidentiality. Scand J Prim Health Care 2003; 21(1): 21-26.

29. Starfield BJ, Simborg DW, Horn SD, Yourtee SA. Continuity and coordination in primary care: their achievement and utility. Med Care 1976; 14(7): 625-636.

30. Desguin BW, Holt IJ, McCarthy SM. Comprehensive care of the child with a chronic condition - part 2. Primary care management. Curr Probl Paediatr 1994; 24(7): 230-248.

31. Errington RD. Coleen - the general practitioner's role in her primary medical care. J R Coll Gen Pract 1974; 24(145): 576-577.

32. Freeman G. Continuity of care in general practice: a review and critique. Fam Pract 1984; 1(4): 245-252.

33. Freeman GK, Olesen F, Hjortdahl P. Continuity of care: an essential element of modern general practice? Fam Pract 2003; 20(6): 623-627.

34. Freer CB. Health diaries: a method of collecting health information. J R Coll Gen Pract 1980; 30(214): 279-282.

35. Guthrie B, Wyke S. Controversy in primary care - does continuit in general practice really matter? BMJ 2000; 321(7263): 734-735.

36. Hegan T. Providing Protection for medical doctors. Med J Malaysia 2003; 58 suppl/A: 141-145.

37. Hennen BK. Continuity of care in family practice - Part 1 : dimensions of continuity. J Fam Pract 1975; 2(5): 371-372.
38. Hjortdahl P. Continuity of care - going out of style? Br J Gen Pract 2001; 51(470): 699-700.

39. Kibbe DC, Phillips RL, Green LA. The continuity of care record. Am Fam Physician 2004; 70(7): 1220-1223.

40. Mandl KD, Szolovits P, Kohand IS. Public standards and patients control: how to keep electronic medical records accessible but private. BMJ 2001; 322(7281): 283-286.

41. Rogers J, Curtis P. The concept and measurement of continuity in primary care. Am J Public Health 1980; 70(2): 122-127.

42. Thompson MK. Hypothesis: old people would benefit from a patient-held standardized primary health care record. Age Ageing 1989 18: 64-66; doi:10.1093/ageing/18.1.64.

43. Crooks VA, Agarwal G. Chronically ill patients' and family caregivers' perspectives on the use of computer technologies in family practice: implications for the development of informational continuity of care. In: JB Garner JB, Christiansen TC (eds). Social sciences in health care and medicine. New York: Nova Science Publishers, 2008; 167-180.

44. Greengross S, Murphy E, Quam L, Rochon P, Smith R. Aging: a subject that must be at the top of world agendas. BMJ 1997; 315: 1029-1010.

45. Joint WHO/FAO Expert Consultation on Diet, Nutrition and the Prevention of Chronic Diseases. Diet, nutrition and the prevention of chronic diseases: report of a joint WHO/FAO expert consultation, Geneva, 28 January-1 February 2002 (WHO technical report series: 916). Geneva: World Health Organization, 2002

46. Abbott S. Equity of access to primary care in the UK: is it likely to increase? Prim Health Care Res Dev 2003; 4: 187-189 